This item is the archived peer-reviewed author-version of:

\title{
Chabazite : stable cation-exchanger in hyper alkaline concrete pore water
}

\section{Reference:}

Van Tendeloo Leen, Wangermez Wauter, Kurttepeli Mert, de Blochouse Benny, Bals Sara, Van Tendeloo Gustaaf, Martens Johan A., Maes André, Kirschhock Christine E.A., Breynaert Eric.- Chabazite : stable cation-exchanger in hyper alkaline concrete pore water

Environmental science and technology / American Chemical Society - ISSN 0013-936X - 49:4(2015), p. 2358-2365

Full text (Publishers DOI): http://dx.doi.org/doi:10.1021/es505346j

To cite this reference: http://hdl.handle.net/10067/1276950151162165141 


\section{Chabazite: Stable cation-exchanger in hyper alkaline}

2 concrete pore water

3 Leen Van Tendeloo, ${ }^{1}$ Wauter Wangermez, ${ }^{1}$ Mert Kurttepeli, ${ }^{2}$ Benny de Blochouse, ${ }^{1}$ Sara Bals, ${ }^{2}$

4 Gustaaf Van Tendeloo, ${ }^{2}$ Johan A. Martens, ${ }^{1}$ André Maes, ${ }^{1}$ Christine E.A. Kirschhock, ${ }^{1}$ Eric

5 Breynaert ${ }^{1, *}$.

$6{ }^{1}$ Centre for Surface Chemistry and Catalysis, KU Leuven, Kasteelpark Arenberg 23 - box 2461,

73001 Heverlee.

$8 \quad{ }^{2}$ Electron Microscopy for Materials Science (EMAT), University of Antwerp,

9 Groenenborgerlaan 171, 2020 Antwerp;

10 cation exchange, cesium, zeolite stability, hyper alkaline media, chabazite, merlinoite, concrete

11 porewater

\section{ABSTRACT}

13 To avoid impact on the environment, facilities for permanent disposal of hazardous waste adopt

14 multi-barrier design schemes. As the primary barrier very often consists of cement-based

15 materials, two distinct aspects are essential for the selection of a suitable complementary

16 barriers: 1) selective sorption of the contaminants in the repository and 2) long-term chemical

17 stability in hyperalkaline concrete derived media. A multidisciplinary approach combining

18 experimental strategies from environmental chemistry and materials science is therefore essential 
19 to provide a reliable assessment of potential candidate materials. Chabazite is typically

20 synthesized in $1 \mathrm{M} \mathrm{KOH}$ solutions, but also crystallises in simulated young cement porewater, a

$21 \mathrm{pH} 13$ aqueous solution mainly containing $\mathrm{K}^{+}$and $\mathrm{Na}^{+}$cations. Its formation and stability in this

22 medium was evaluated as function of temperature $\left(60\right.$ and $\left.85^{\circ} \mathrm{C}\right)$ over a timeframe of more than

232 years and was also asessed from a mechanistic point of view. Chabazite demonstrates excellent

24 cation exchange properties in simulated young cement porewater. Comparison of its $\mathrm{Cs}^{+}$cation

25 exchange properties at $\mathrm{pH} 8$ and $\mathrm{pH} 13$ unexpectedly demonstrated an increase of the $\mathrm{K}_{\mathrm{D}}$ with

26 increasing $\mathrm{pH}$. The combined results identify chabazite as a valid candidate for inclusion in

27 engineered barriers for concrete based waste disposal.

INTRODUCTION

29 Despite all efforts towards selective waste collection and consequent recycling, non-reusable

30 and hazardous waste fractions remaining at the end of the revalorization chain, require long-term

31 storage or permanent disposal.[1, 2] One example is the low- and medium-level, short-lived

32 conditioned radioactive waste (in a Belgian context, category A waste ), [3] which has to be

33 stored safely for several decades up to centuries. As for chemotoxic waste, a feasible scenario for

34 this waste involves immobilization and isolation in concrete-based surface disposal facilities.[1-

356 6] The concrete acts as the main barrier in preventing the radionuclides from entering the

36 biosphere. In order to increase the robustness of a disposal system complementary barriers can

37 be implemented. Such a complementary barrier should combine long term stability in hyper-

38 alkaline aqueous media with suitable sorption properties (high selectivity and excess capacity).

39 Indeed, upon water intrusion and consequent rehydration of the concrete, the first cement

40 degradation stage generates hyper-alkaline, saline pore water $\left(0.1-1 \mathrm{M} \mathrm{OH}^{-}, 0.1-1 \mathrm{M}\right.$ alkaline

41 cations) due to dissolution of $\mathrm{Na}_{2} \mathrm{O}$ and $\mathrm{K}_{2} \mathrm{O}$ (See Table SI- 1 for typical composition).[7, 8] 
42 Prefereably, the sorption sink should be unsuitable as substrate for bacteria proliferation. In view

43 of all these limitations, zeolites are among the few commercially available materials remaining

44 on the shortlist of potentially suitable sorption sinks.

45 While the structure of a zeolite framework can be probed with several physicochemical 46 characterization techniques such as XRD and NMR, chemical probes can be assumed to be more 47 sensitive to detect zeolite hydrolysis, small changes in framework composition, and/or 48 aluminium distribution. Since the affinity of an ion exchanger for specific ions (e.g. $\mathrm{Cs}^{+} \mathrm{vs} \mathrm{Na}^{+}$) 49 is highly dependent on the surface charge density,[9-12] specific ions can be exploited as a probe 50 for the site selectivity and hence charge distribution of a cation exchanger. $\mathrm{Cs}^{+}$has been adopted 51 as a proxy to assess the potential use of zeolites in complementary barriers because it is a well-

52 known species in neutral conditions exhibiting high sorption on zeolites.[13-23] While zeolite 53 types such as CHA, HEU and MOR are known to selectively retain $\mathrm{Cs}^{+}$cations through ion54 exchange, reports on their application and stability in hyper-alkaline aqueous media are scarce $55[18,24,25]$. However, CHA is among the few framework types that have been reported to form 56 upon interaction of young concrete pore water (YCW) with natural aluminosilicates. 57 Equilibrating bentonite with simulated concrete pore water for a period of 2 years, Fernandez et 58 al. observed the formation of chabazite at both 60 and $90{ }^{\circ} \mathrm{C}$, and merlinoite at $90^{\circ} \mathrm{C}$. [26] Also 59 by reacting sediments containing chlorite as the dominant clay mineral with YCW for 1 year at $6070^{\circ} \mathrm{C}$, chabazite was formed.[27] Within the timeframe of these studies, no zeolite formation was 61 detected at room temperature.

62 Next to these studies of zeolite formation upon sediment interaction with YCW, interaction of 63 zeolites with inorganic hyper-alkaline aqueous media is also investigated and exploited for 64 zeolite production. Indeed, hyper-alkaline transformation of synthetic zeolites based on 
65 solubilization, followed by nucleation and growth of a new phase, is actively explored as a

66 means to easily synthesize various zeolite types using cheap zeolitic starting materials (e.g.

67 FAU).[28-30] In addition to easy access to industrially important frameworks, these experiments

68 also allow extrapolation on the stability of zeolite frameworks in high alkaline conditions: The

69 understanding of hyperalkaline transformation of zeolites, subsequently yielding stable phases in

70 a specific medium, could add confidence towards long-term safety of zeolites as sorption sinks.

71 This approach demonstrating the affinity for a specific framework to form and to be stabilized in

72 high alkaline conditions, offers added value to the mere observation that this zeolite remains

73 unaltered by short term exposure to $\mathrm{YCW}$.

74 Estimation of zeolite stability in hyper-alkaline solutions (e.g. concrete pore water) over a

75 timeframe of tens of decades, ultimately requires elucidation of the mechanism responsible for

76 the (de)stabilizing effects of alkaline cations on zeolite structures. Therefore, this study aimed at

77 enhancing insight into zeolite transformation processes and revealing the role of alkali metal

78 cations therein. To increase confidence in the results, the zeolite transformation study in multiple

$79 \mathrm{Na} / \mathrm{K}$ based hyper-alkaline media as function of temperature, was combined with a chemical

80 assessment of the stability of the main transformation product, chabazite, via time-dependent

81 evaluation of its affinity for $\mathrm{Cs}^{+}$exchange.

\section{EXPERIMENTAL SECTION}

83 Materials. A commercial zeolite $\mathrm{Na}-\mathrm{Y}$ (Zeocat, $\mathrm{Si} / \mathrm{Al}=2.65)$ was used as starting material for

84 the transformation study in concrete pore water. In addition, micron sized zeolite $\mathrm{Y}$ crystals were

85 synthesized according to a recipe from Feijen et al. [31] using a batch composition $10 \mathrm{SiO}_{2}$ :

$86 \mathrm{Al}_{2} \mathrm{O}_{3}: 2.40 \mathrm{Na}_{2} \mathrm{O}: 1$ 15-crown-5: $135 \mathrm{H}_{2} \mathrm{O}$. To remove the 15-crown-5 template, the zeolite 
87 powder was calcined in air for 10 hours at $550^{\circ} \mathrm{C}$, with a heating rate of $2^{\circ} \mathrm{C} / \mathrm{min}$. The Si/Al ratio 88 of the calcined Na-Y was determined as 3.50 by ${ }^{29} \mathrm{Si}$ MAS NMR.

89 Chabazite for the sorption experiment was synthesized by hydrothermal transformation of 90 zeolite Y (Zeocat) according to the IZA recipe, [32] originally reported by Bourgogne et al.[33]

$91 \mathrm{Ca}-\mathrm{Y}$ was obtained by ion-exchange of calcined $\left(\mathrm{NH}_{4}, \mathrm{Na}\right)-\mathrm{Y}$ (CBV300, Zeolyst) with $1 \mathrm{M}$ $92 \mathrm{CaCl}_{2}$.

93 Transformation study. For the transformations in $\mathrm{YCW}$, zeolite $\mathrm{Na}-\mathrm{Y}(\mathrm{Zeocat}, \mathrm{Si} / \mathrm{Al}=2.65)$

94 was used. All batch systems consisted of $40 \mathrm{~mL}$ Oak Ridge polypropylene (PP) centrifuge tubes 95 with screw caps containing $500 \mathrm{mg}$ of zeolite Na-Y powder, sieved between 100 and $200 \mu \mathrm{m}$. 96 Upon addition of $20 \mathrm{~mL}$ of simulated YCW, the gross weight of the batch systems was logged 97 for future reference. One series of 20 tubes was placed in a rotary oven at $85^{\circ} \mathrm{C}$, while a second 98 series was incubated statically at $60^{\circ} \mathrm{C}$. To correct the liquid volume lost due to water vapour 99 diffusion through the PP tube, the tubes were topped up with milliQ water on a weekly basis for 100 the tubes incubated at $85^{\circ} \mathrm{C}$ and on monthly basis in the case of the series incubated at $60^{\circ} \mathrm{C}$. The 101 chemical equilibria in the systems were evaluated as function of time by sacrificial analysis of 102 the components of one batch system for each evaluation time. At each evaluation time, one 103 system was cooled to room temperature, centrifuged and decanted. The $\mathrm{pH}$ of the supernatant 104 was measured and the pellet was dried overnight at $60^{\circ} \mathrm{C}$.

$105 \mathrm{Na}-\mathrm{Y}(\mathrm{Si} / \mathrm{Al}=3.5)$ was immersed in $1.2 \mathrm{M} \mathrm{KOH}(\mathrm{VWR}, \min .85 \%)$. All batch systems of this 106 series consisted of centrifuge tubes with screw caps containing $300 \mathrm{mg}$ of Na-Y and $18 \mathrm{~mL}$ of 107 hydroxide solution. The PP tubes were placed in a rotary oven at $85^{\circ} \mathrm{C}$. At each evaluation time, 108 one system was cooled to room temperature, centrifuged and decanted. The liquid was 
109 immediately diluted 50 and 500 times with milliQ water. The solids were washed with water and 110 dried at $60^{\circ} \mathrm{C}$ before characterization.

$111 \mathrm{Ca}-\mathrm{Y}$ was exposed to $1 \mathrm{M} \mathrm{KOH}$ at $95^{\circ} \mathrm{C}$, using a liquid/solid ratio of 9 .

112 YCW. Simulated state I concrete pore water (pH 13) was obtained by mixing $500 \mathrm{~mL}$ Milli-Q 113 water, $0.0296 \mathrm{~g} \mathrm{Ca}(\mathrm{OH})_{2}\left(4 \cdot 10^{-4} \mathrm{~mol}\right), 10 \mathrm{~mL} \mathrm{Na}_{2} \mathrm{CO}_{3}$ solution $\left(10^{-2} \mathrm{M}\right), 180 \mathrm{~mL} \mathrm{KOH}(1 \mathrm{M}), 70$

$114 \mathrm{~mL} \mathrm{NaOH}$ solution $(1 \mathrm{M})$, and $0.189 \mathrm{~g} \mathrm{CaSO}_{4} \cdot 2 \mathrm{H}_{2} \mathrm{O}\left(1.1 \cdot 10^{-3} \mathrm{~mol}\right)$ in this order. Upon complete 115 dissolution of all components, the solution was made up to $1 \mathrm{~L}$ with Milli-Q water.

116 A moderate $\mathrm{pH}$ counterpart of the state I concrete pore water $(\mathrm{pH} 8)$ was prepared in a $1 \mathrm{~L}$ 117 volumetric flask by dissolving respectively $0.189 \mathrm{~g}$ of $\mathrm{CaSO}_{4} .2 \mathrm{H}_{2} \mathrm{O}\left[1.1 \times 10^{-3}\right.$ moles $]$ and 0.0945 $118 \mathrm{~g}$ of $\mathrm{Ca}\left(\mathrm{NO}_{3}\right)_{2} .4 \mathrm{H}_{2} \mathrm{O}$ in $500 \mathrm{~mL}$ of MilliQ water, followed by addition of $10 \mathrm{~mL}$ of a $10^{-2} \mathrm{M}$ $119 \mathrm{NaHCO}_{3}$ solution, $180 \mathrm{~mL}$ of a $1 \mathrm{M} \mathrm{KNO}_{3}$ solution, $70 \mathrm{~mL}$ of a $1 \mathrm{M} \mathrm{NaNO}$ solution. After 120 complete dissolution of all components the total volume was made up to 1 L by addition of 121 MilliQ water, immediately followed by a transfer of the solution to a closed $1 \mathrm{~L}$ polypropylene 122 bottle.

123 Equilibrium speciation for the major elements was calculated with Phreeqc [34], in combination 124 with the Lawrence Livermore National Laboratory database llnl.dat.

125 Characterization. The evolution of the solids was evaluated by XRD analysis. High 126 resolution XRD patterns were recorded on a STOE STADI MP diffractometer with focusing $127 \mathrm{Ge}(111)$ monochromator $\left(\mathrm{CuK} \alpha_{1}\right.$ radiation) in Debye-Scherrer geometry with a linear position 128 sensitive detector (PSD) $\left(62^{\circ} \theta\right.$ window) with a step width of 0.5 degree and internal PSD 129 resolution 0.01 degree. High throughput PXRD screening was performed on a STOE STADI P 130 Combi diffractometer with focusing $\mathrm{Ge}(111)$ monochromator $\left(\mathrm{CuK} \alpha_{1}\right.$ radiation) in transmission 
131 geometry with $140^{\circ}$-curved image plate position sensitive detector (IP PSD) from with internal 132 IP PSD resolution of 0.03 degree.

133 ICP-AES was used to determine $\mathrm{Si}$ and $\mathrm{Al}$ in supernatant solutions.

134 Scanning electron microscopy (SEM) was performed using a FEI Helios NanoLab 650 dual135 beam system to resolve the morphology of the zeolitic crystals during the transformation in pure $136 \mathrm{KOH}$. The products formed in YCW were studied using a FEI-Nova Nano-SEM 450. 137 Transmission electron microscopy (TEM) specimens were prepared by applying drops of ethanol 138 suspension of the powder sample on a carbon coated copper grid. High-resolution TEM 139 (HRTEM) was performed using a FEI Tecnai F20 operated at $200 \mathrm{kV}$.

140 Tilt series for electron tomography were acquired with the FEI Tecnai F20 operated at $200 \mathrm{kV}$ 141 in combination with an advanced tomography holder from Fischione Instruments and the FEI 142 XPlore3D acquisition software. Tilt series consisting of 75 HAADF-STEM images were 143 acquired with tilt increments of $2^{\circ}$ over a range of $\pm 74^{\circ}$ on TEM samples. Alignment of the data 144 was carried out using the FEI Inspect3D software package. The reconstruction was performed 145 using the "Simultaneous Iterative Reconstruction Technique" (SIRT) with 25 iterations 146 implemented in Inspect3D. Amira (Visage Imaging $\mathrm{GmbH}$ ) was used for the visualization of the 147 reconstructed volume. An animated version of the tomogram is also provided in the supporting 148 information as video.

149 A Bruker AMX300 spectrometer (7.0 T) was used to record ${ }^{29} \mathrm{Si}$ MAS NMR spectra of powder 150 samples packed in $4 \mathrm{~mm}$ Zirconia rotors spun at a spinning frequency of $6 \mathrm{kHz}$. The resonance 151 frequency of ${ }^{29} \mathrm{Si}$ at this field is $59.63 \mathrm{MHz} .1000$ to 4000 scans were accumulated with a recycle 152 delay of $60 \mathrm{~s}$ and a pulse length of $5.0 \mu \mathrm{s}$. The chemical shift reference used was 153 tetramethylsilane (TMS). A Bruker Avance DSX400 spectrometer (9.4 T) was used to record the 
$154{ }^{27}$ Al MAS NMR spectra of spinning $(20 \mathrm{kHz})$ powder samples in $2.5 \mathrm{~mm}$ Zirkonia rotors with an

$155{ }^{27} \mathrm{Al}$ resonance frequency of 104.26 MHz. Data was recorded using single-pulse excitation, 156 accumulating 36000 scans with a recycle delay of $100 \mathrm{~ms}$ and pulse length of $0.30 \mu \mathrm{s}$. All 157 chemical shifts are reported relative to the reference shift of $0.1 \mathrm{M}$ aqueous solution of $158 \quad \mathrm{Al}\left(\mathrm{NO}_{3}\right)_{3} .9 \mathrm{H}_{2} \mathrm{O}(0 \mathrm{ppm})$.

159 Cs sorption. Cs sorption experiments were run using ${ }^{137} \mathrm{Cs}$ spiked solutions. ${ }^{137} \mathrm{Cs}$ was 160 purchased from Polatom as carrier-free ${ }^{137} \mathrm{CsCl}$ dissolved in $0.1 \mathrm{M} \mathrm{HCl}$. Upon arrival, this 161 solution $\left(0.1 \mathrm{~mL} ; 925 \mathrm{MBq} \mathrm{cm}^{-3} ; 3220 \mathrm{GBq} \mathrm{g}^{-1} ; 2.1 \times 10^{-3} \mathrm{M} \mathrm{Cs}^{+}\right)$was diluted 10 times with MQ 162 water in the conical bottom vial in which the spike was delivered. For the sorption experiments, 163 this initial stock solution was further diluted with stable $\mathrm{CsNO}_{3}$ solutions prepared in the 164 respective concrete pore water or mono-ionic electrolyte solution to reach a final ${ }^{137} \mathrm{Cs}$ 165 concentration of $3.1 \times 10^{-12} \mathrm{M}$.

$166100 \mathrm{mg}$ of the zeolite, previously equilibrated with $\mathrm{YCW}$, was mixed with $20 \mathrm{~mL}$ of its 167 respective ${ }^{137} \mathrm{Cs}$ spiked concrete pore water with varying concentrations of $\mathrm{CsCl}\left(10^{-4}, 10^{-5}, 10^{-6}\right.$, $1685 \times 10^{-7}, 10^{-7}$ and $10^{-10}$ ) in Oak Ridge centrifuge tubes. These tubes were equilibrated together 169 with their respective blanks (Cs-containing pore water without zeolite) at $25^{\circ} \mathrm{C}$ on a rotary 170 shaker. After different equilibration times, the samples were centrifuged at $25^{\circ} \mathrm{C}$ with a cut-off of $17185 \mathrm{~nm}$ (Beckman, J2-HS, JA-17, $20 \mathrm{~min}, 10000 \mathrm{rpm}, 25^{\circ} \mathrm{C}$ ). Upon centrifugation 1ml aliquots of 172 the supernatant phase were transferred to liquid scintillation vials, mixed with 2 ml Ultima Gold 173 XR (Packard) scintillation gel and counted in a Tricarb 2800 (Packard) liquid scintillation 174 counter.

175 Chabazite standardization and pre-equilibration in YCW. The chabazite powder was 176 sieved over a $50 \mu \mathrm{m}$ stainless steel Retsch sieve (DIN-ISO: 3310/1) using a pH 8.5 $\mathrm{NaOH}$ 
177 solution prepared from twice distilled water. The zeolite fraction passing the sieve was then

178 transferred to $250 \mathrm{~mL}$ centrifuge cups while adjusting the total volume to $250 \mathrm{~mL}$. In a next step,

179 the suspension was centrifuged with a cut-off of $1 \mu \mathrm{m}$ (JA-14, $5 \mathrm{~min}, 2000 \mathrm{rpm})$ to obtain the

180 zeolite fraction with dimensions between 1 and $50 \mu \mathrm{m}$. After centrifugation $200 \mathrm{~mL}$ of the

181 supernatant solution was discarded, followed by addition of $200 \mathrm{~mL}$ of a $1 \mathrm{~N} \mathrm{NaNO}_{3}$ solution

182 titrated to $\mathrm{pH} 8.5$ with $\mathrm{NaOH}$. Following re-suspension of the pellet, the system was equilibrated

183 overnight on an end-over-end shaker and subsequently centrifuged with a cut-off of $1 \mu \mathrm{m}$, while

184 discarding the supernatant solution. This washing step was repeated 3 times to obtain a well-

185 defined sodium exchanged zeolite fraction with dimensions between 1 and $50 \mu \mathrm{m}$. The resulting

186 Na-form zeolite material was then desalinated by three additional washing steps of 15 minutes;

187 initially with $0.1 \mathrm{~N} \mathrm{NaNO}_{3}$ solutions at $\mathrm{pH} 8$ and afterwards twice with ultrapure water (MilliQ)

188 titrated to $\mathrm{pH} 8$ with $\mathrm{NaOH}$. The resulting standardized material was dried at $65^{\circ} \mathrm{C}(96 \mathrm{~h})$ and

189 subsequently stored in an exsiccator over a saturated $\mathrm{LiCl}$ solution.

190 During pre-equilibration $2 \mathrm{~g}$ of standardized chabazite in its Na-form were washed three times

191 for $24 \mathrm{~h}$ at $25^{\circ} \mathrm{C}$ with $20 \mathrm{~mL}$ of the respective concrete pore water. After every washing step the

192 zeolite was separated from the supernatant by centrifugation (Beckman, J2-HS, JA-17, 5min,

$1932000 \mathrm{rpm}, 25^{\circ} \mathrm{C}$ ) and $17 \mathrm{ml}$ of the supernatant solution was exchanged with new concrete pore

194 water solution. Following pre-equilibration the zeolite material was washed twice with MilliQ

195 water (15 minutes) to remove the interstitial solutions; centrifuged at 7000rpm for 10 minutes to

196 allow removing the maximum amount of supernatant solution and dried at $65^{\circ} \mathrm{C}(72 \mathrm{~h})$. The dried

197 material was stored in an exsiccator over a saturated $\mathrm{LiCl}$ solution until further use. 
${ }^{137} \mathrm{Cs}^{+}$sorption. Cation exchange isotherms recorded as function of time for a highly selective

202 ion like $\mathrm{Cs}^{+}$, provide a sensitive probe for small changes in site selectivity and availability [9,

203 10], and hence offer a means to assess zeolite stability as function of time. $\mathrm{Cs}^{+}$sorption data for

204 chabazite $(\mathrm{Si} / \mathrm{Al}=2.1)$, synthesized using FAU-type zeolite, show constant initial $\mathrm{K}_{\mathrm{D}}$ values

205 around $5501 \mathrm{~kg}^{-1}$ in YCW electrolyte solution with concentration range of $10^{-10}$ to $10^{-4} \mathrm{M} \mathrm{Cs}^{+}$. In

206 the timeframe from 1 to 105 days, $K_{D}$ slightly decreased, but remained higher than $5001 \mathrm{~kg}^{-1}$

207 (Figure 1).

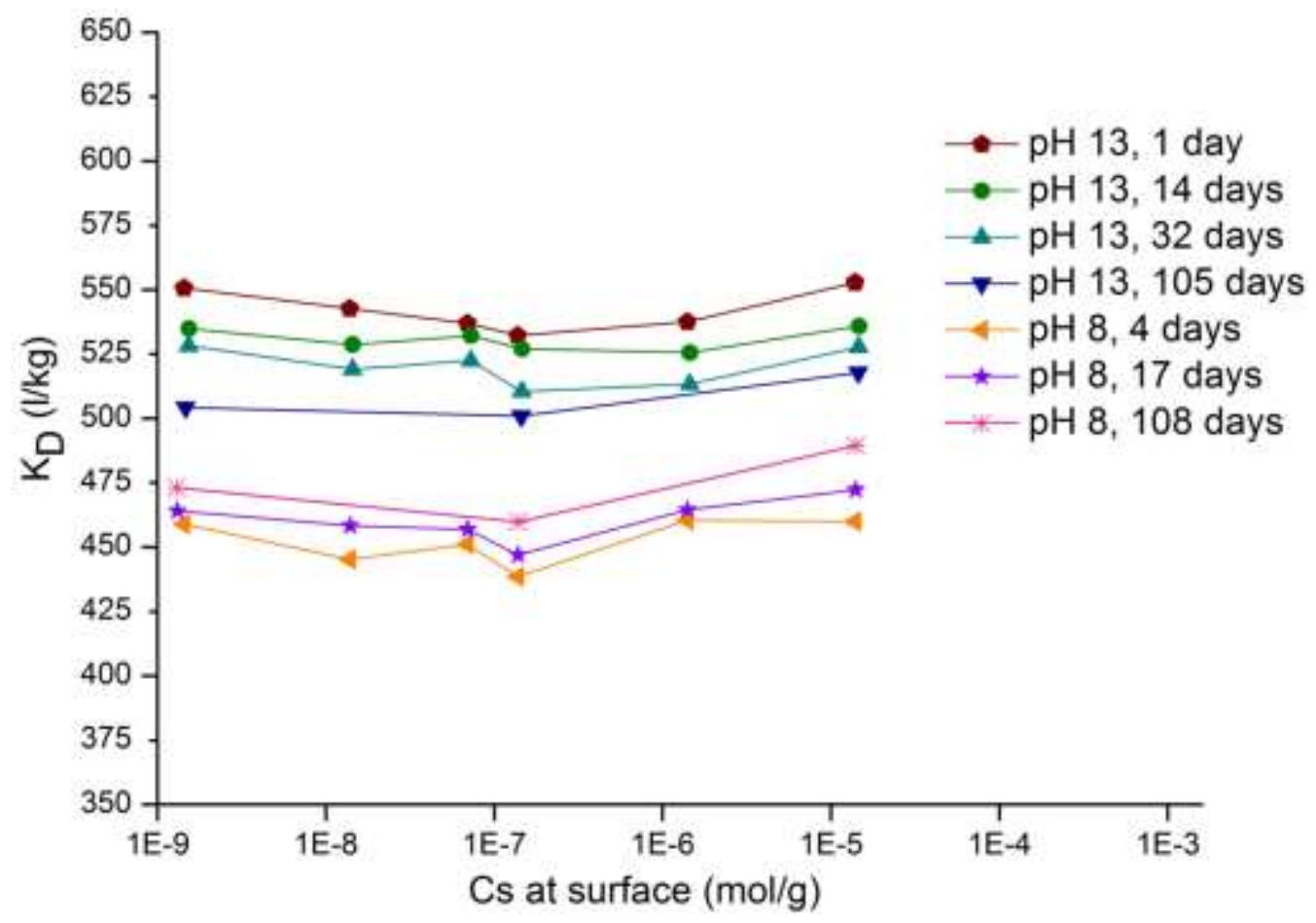

Cs at surface $(\mathrm{mol} / \mathrm{g})$

209 Figure 1. $\mathrm{Cs}^{+}$exchange on chabazite equilibrated with concrete pore water. The standard 210 deviation $(1 \sigma)$ calculated for the reported $K_{D}$ values are $\pm 21 \mathrm{~kg}^{-1}$.

211 In related electrolyte solutions at $\mathrm{pH} 8$ (See Table SI- 2 for composition), the observed $\mathrm{K}_{\mathrm{D}}$ 212 values (460 $1 \mathrm{~kg}^{-1}$ ) were significantly lower, showing a slight upward trend with time.

213 Consequently, hydroxyl induced structural alteration is considered as the most likely explanation

214 both for increased $\mathrm{K}_{\mathrm{D}}$ with increasing $\mathrm{pH}$, and slight time-dependent decrease of the 
215 hyperalkaline distribution coefficients, which cannot be attributed to slow diffusion of $\mathrm{Cs}^{+}$into

216 the zeolite structure. As the high selectivity of chabazite for $\mathrm{Cs}^{+}$, previously documented in

217 circumneutral conditions,[18] now also has been established in hyper alkaline cementitious

218 environment, evaluation of the framework stability remains the most important prerequisite to

219 enable long-term application in such conditions.

220 Short-term zeolite stability can be verified by structural characterization of a sample series

221 equilibrated in hyper alkaline media as function of time. A similar evaluation of the long-term

222 stability over decades and centuries is experimentally unfeasible and should be approached

223 differently. Recently, hyper alkaline transformation from zeolite Y (FAU) to various zeolite

224 topologies by exposure to different alkali cations was demonstrated,[28] in analogy to the

225 formation of CHA from FAU in $1 \mathrm{M} \mathrm{KOH}$, originally reported by Bourgogne et al.[33] By

226 exposure of FAU type zeolite to hydroxide solution $(1 \mathrm{M})$ at $95^{\circ} \mathrm{C}$, phase pure $\mathrm{ABW}, \mathrm{CHA}$,

227 MER and ANA frameworks were obtained within 4 days using $\mathrm{LiOH}, \mathrm{KOH}, \mathrm{RbOH}$ and $\mathrm{CsOH}$,

228 respectively. Recrystallization in $\mathrm{NaOH}$ occurred much slower, yielding only traces of zeolite $\mathrm{P}$

229 after 4 days. Since YCW essentially is a hyper alkaline solution containing $0.18 \mathrm{M} \mathrm{KOH}$ and

$2300.07 \mathrm{M} \mathrm{NaOH}$, transformation of FAU into CHA is also expected in such media, which would

231 provide a first hint towards chabazite long-term stability in YCW. Subsequent observation of

232 short-term stability and the mechanistic understanding of framework transformations are

233 currently considered as the most feasible and reliable pathway for gaining insight into the long-

234 term stability of CHA in cement derived pore water solutions.

235 Zeolite $\mathbf{Y}$ transformation in YCW. Commercial zeolite Na-Y (Zeocat) was exposed to

236 simulated state I concrete pore water ( $\mathrm{pH}$ 13), instead of pure $1 \mathrm{M}$ alkali metal hydroxide

237 solution. As the $\mathrm{K} / \mathrm{Na}$ ratio of the pore water is $2.5 / 1$, chabazite was expected to form, but only 
238 after a longer incubation period due to the lower total hydroxide concentration, resulting in a

239 slower hydrolysis of the zeolite $\mathrm{Y}$ framework.[35] The XRD patterns shown in Figure 2

240 demonstrate that only after 91 days at $85^{\circ} \mathrm{C}$ the (100) reflection of chabazite appears at $9.52^{\circ} 2 \theta$.

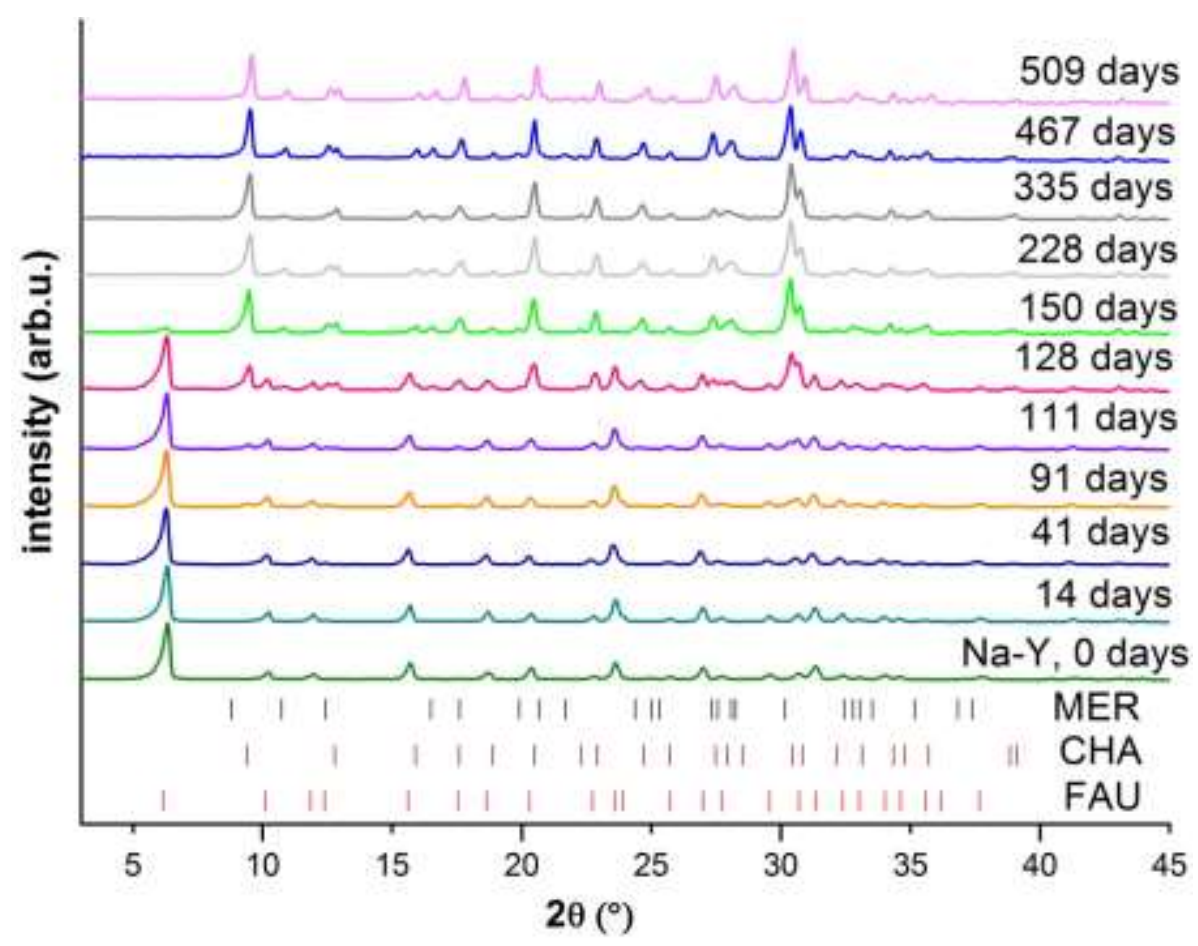

242 Figure 2. Transformation of zeolite $\mathrm{Y}$ in simulated $\mathrm{YCW}$ at $85^{\circ} \mathrm{C}$ under rotation. The presence of CHA type zeolite is detected after 91 days.

244 This indicates transformation has been initiated between 41 and 91 days. After 150 days, 245 zeolite $\mathrm{Y}$ is almost fully transformed. Further XRD patterns of the solid phase products sampled 246 up to 509 days remain similar, indicating that a product, stable in concrete pore water, is 247 obtained. This product is a mixture of chabazite and merlinoite (MER). A MER fraction is 248 already clearly present in the 150 days sample (Figure 2), when FAU is not yet fully 249 transformed, and has not distinctly increased after 509 days. In the series of zeolite Y exposed to 250 concrete pore water at $60^{\circ} \mathrm{C}$ in static conditions, reflections of chabazite appeared between 224 251 to 299 days (Figure 3), implying a significant delay of chabazite nucleation at $60^{\circ} \mathrm{C}$ compared to 
$25285^{\circ} \mathrm{C}$. The analysis of the last sample, separated after 837 days, revealed an almost complete 253 transformation of zeolite Y. In Figure 4, the powder XRD patterns of the transformation products 254 of both temperature series are compared, showing that also in the low temperature series a MER 255 type side phase is present next to chabazite. Due to potential differences in water content and 256 chemical composition of these porous samples, the relative amount of both phases is only 257 precisely determined by the Rietveld refinement method.

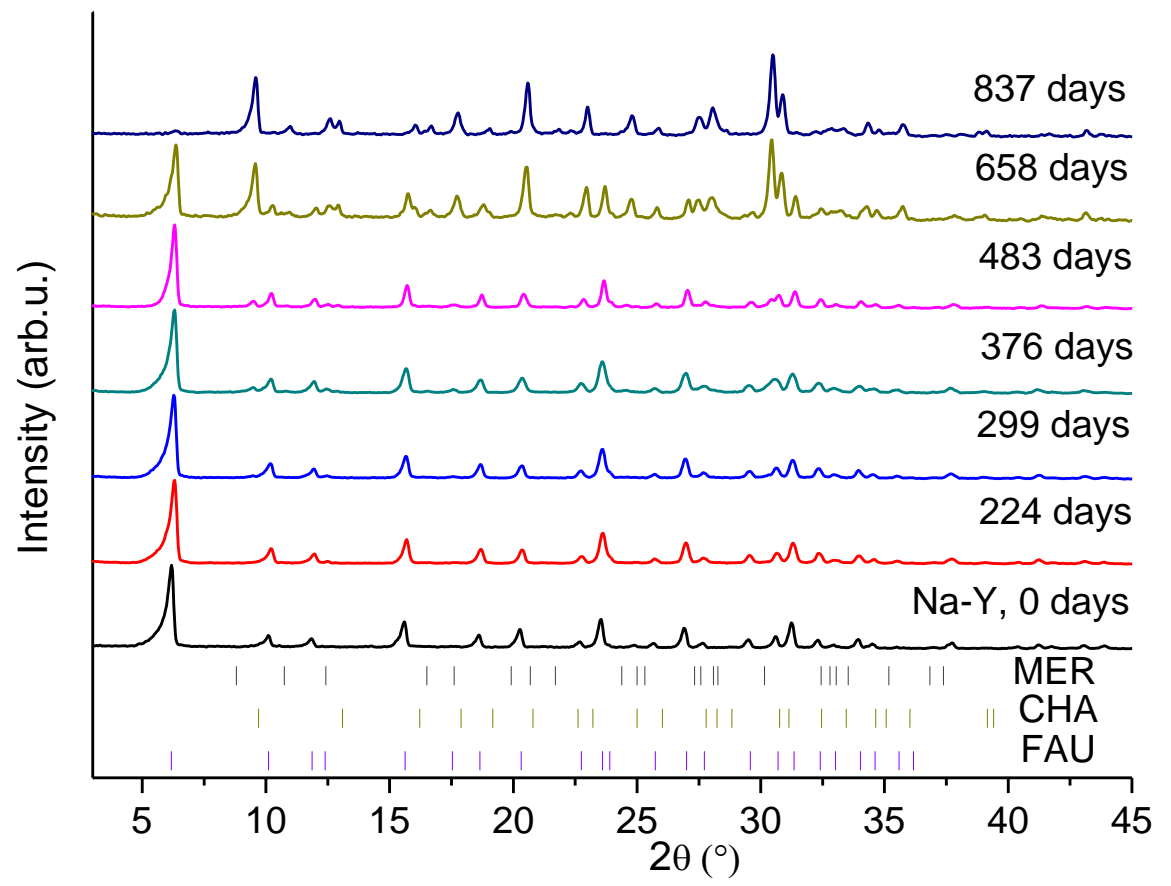

259 Figure 3. Transformation of zeolite $\mathrm{Y}$ in simulated $\mathrm{YCW}$ at $60^{\circ} \mathrm{C}$ (static). $\mathrm{CHA}$ is detected after 299 days. 


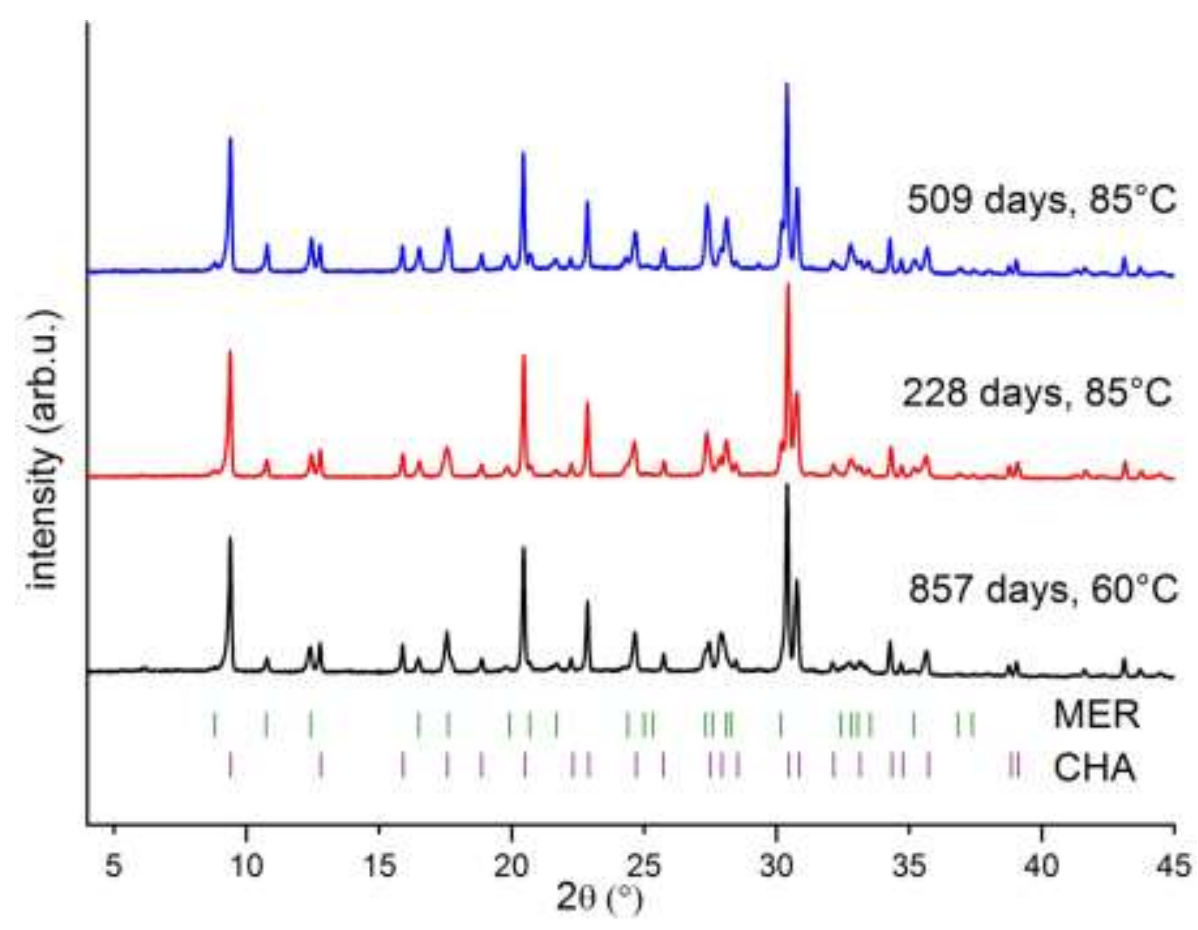

262 Figure 4. Comparison of the (hydrated) products of the transformation series at $60^{\circ} \mathrm{C}$ and $85^{\circ} \mathrm{C}$.

263 SEM analysis of the fully transformed products (Figure 5) shows large (up to $50 \mu \mathrm{m}$ ) twinned 264 MER type zeolite rods,[36] which are easily distinguished from the 1-2 micron clustered CHA 265 crystals in the samples. From the SEM images, it is clear that the mixture formed at $60^{\circ} \mathrm{C}$ 266 contains significantly less MER type crystals relative to CHA (Figure SI 1). At $85^{\circ} \mathrm{C}$, no 267 indication for an significant change of the MER/CHA ratio was observed with time.
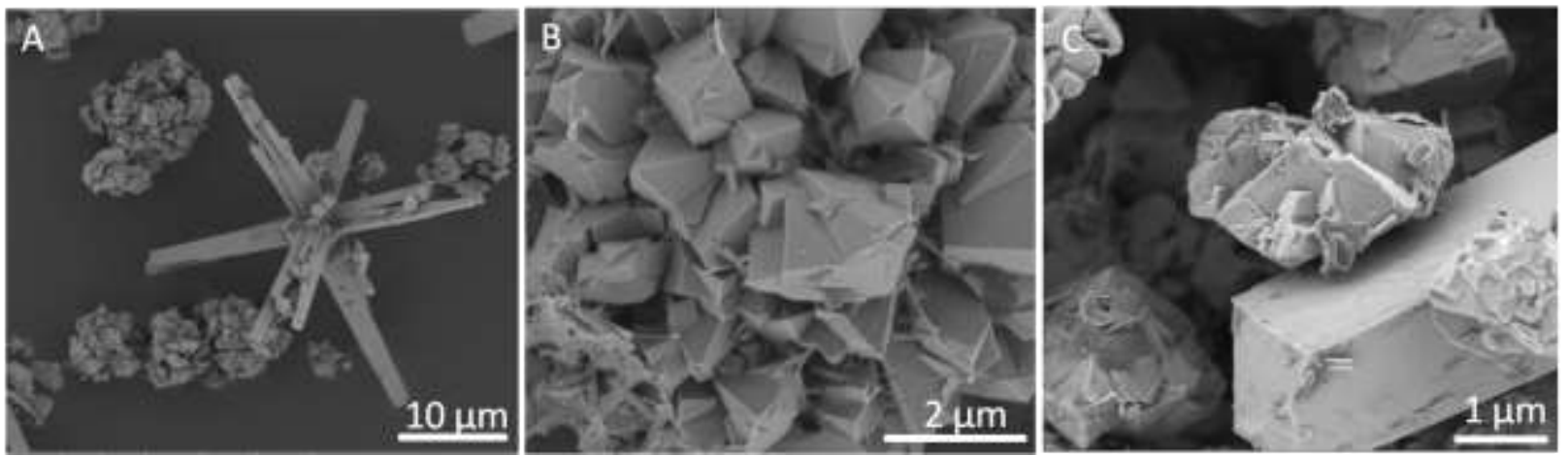
Figure 5. SEM images of the products of the $85^{\circ} \mathrm{C}$ series: A) MER rods with aggregated CHA

270 crystals (228 days sample) B) Detail of the CHA fraction (228 days sample), C) MER and CHA

271 type crystal (509 days sample).

272 The appearance of MER in the YCW based transformation was rather unexpected. Although

273 synthetic merlinoite is typically produced by direct synthesis using batch compositions similar to

274 those resulting in chabazite, MER is only obtained by increasing either the temperature, or the

$275 \mathrm{~K}^{+}$concentration relative to the synthesis composition for CHA synthesis [32, 37] In case of the

276 exposure of FAU to pure $\mathrm{KOH}$, transformation to chabazite was found to occur in a broad range

277 of conditions, and at most trace amounts of MER were encountered, especially at increased

278 temperatures. Once formed in experiments using pure $1 \mathrm{M} \mathrm{KOH}$ solutions at $85^{\circ} \mathrm{C}$, phase pure

279 chabazite remained stable for more than 2 months, without any appearance of MER.

280 Nevertheless, the occurrence of MER in the transformation of zeolite $\mathrm{Y}$ in state I concrete pore

281 water does corroborate results from Fernandez et al.,[26] observing MER as the main

282 transformation product in the reaction of FEBEX bentonite with alkaline pore water $(\mathrm{pH}=13.5)$

283 at $90^{\circ} \mathrm{C}$. Using SEM, Fernandez et al. demonstrated the growth of MER at the expense of CHA

284 and formulated a hypothesis that a structure directing factor in montmorillonite induced

285 formation of metastable chabazite, which readily transforms to MER.[26] Within the timeframe

286 studied in this work, no clear evidence of chabazite transforming into merlinoite was obtained.

287 However, in the final sample of the series at $85^{\circ} \mathrm{C}$, the chabazite crystal surfaces become less

288 smooth and show pitting (Figure $5 \mathrm{C}$ ). Combining results reported in literature with the here

289 observed difference observed for FAU conversion in pure $\mathrm{KOH}$ versus concrete pore water, it

290 seems obvious MER formation is favoured by slow conversion (lower $\mathrm{pH}$ ) in systems containing

$291 \mathrm{Ca}^{2+}$ (and $\left.\mathrm{Mg}^{2+}[26]\right)$ in combination with $\mathrm{K}^{+}$. 
293 solutions nowadays is a standard method to synthesize phase pure CHA, full understanding of

294 the mechanism of this transformation is lacking. For elucidation of this mechanism, it is essential

295 to complement the information available from bulk characterization of solid and liquid phases,

296 with techniques providing more local information such as electron or atomic force

297 microscopy.[38, 39] Since the irregular size and morphology of commercially available zeolite Y

298 crystals prevent unambiguous evaluation of the transformation process, well-defined $1 \mu \mathrm{m}$

299 octahedral crystals were synthesized with a crown ether template. Upon exposure of this zeolite

$300(\mathrm{Si} / \mathrm{Al}=3.5)$ to $\mathrm{KOH}$ solution, liquid phase characterization of the supernatant solutions

301 demonstrated a steadily increasing $\mathrm{Si}$ concentration between 0 and 7 hours of equilibration

302 (Figure SI 2). Compared to $\mathrm{Si}$, the $\mathrm{Al}$ content in solution not only was significantly lower, its

303 concentration did only increase during first 40 minutes, followed by a steady decrease until at

304 complete phase transformation almost no Al was left in solution.

305 Only after 22 hours of treatment with $\mathrm{KOH}$ at $85^{\circ} \mathrm{C}$ PXRD showed reflections of $\mathrm{CHA}$ in 306 addition to the reflections of the FAU starting material (Figure SI 3).

307 Electron Microscopy A SEM study of the solid phases during the FAU-CHA transformation 308 process indicated the nucleation of particles commencing initially at the crystal facets of the 309 FAU starting material already after 7 hours (Figure 6), which coincides with the stabilization of 310 the Si concentration in the supernatant solution. Fast Fourier transformation (FFT) patterns 311 collected from different regions on high resolution TEM images of the sample showed 312 crystalline order in accordance with sets of lattice planes originating from a single crystalline 313 CHA phase (Figure SI 4), on top of the the still persisting FAU crystals. The similarity in the 314 PXRD peak profiles indicated no significant loss of crystallinity of remaining FAU during the 
315 transformation (Figure SI 3). According to the SEM analysis, transformation of FAU into

316 submicron sized CHA crystals was complete in $72 \mathrm{~h}$ (Figure 6). In addition, it should be noted

317 that the chabazite crystals observed in presence of pure $\mathrm{KOH}$ are significantly smaller compared

318 to those obtained in YCW after longer exposure times.
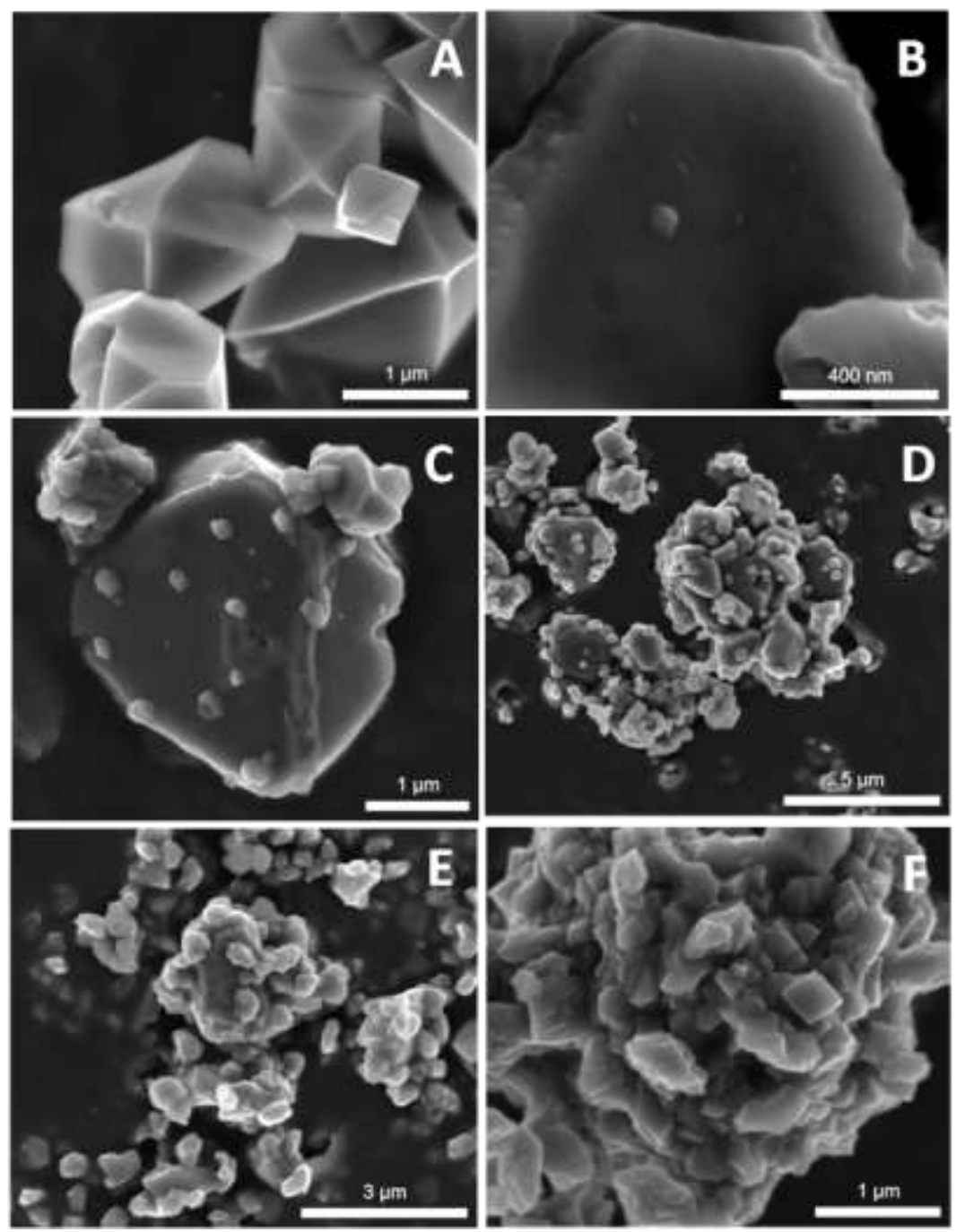

320 Figure 6. SEM images of the transformation products recorded after $0 \mathrm{~h}(\mathrm{~A}), 7 \mathrm{~h}(\mathrm{~B}), 22 \mathrm{~h}(\mathrm{C})$,

$32136 \mathrm{~h}(\mathrm{D}), 60 \mathrm{~h}(\mathrm{E})$ and $72 \mathrm{~h}(\mathrm{~F})$.

322 Electron tomography results showed that after few hours in hydroxide solution, the zeolite $\mathrm{Y}$

323 crystals were etched (Figure 7). After 22 hours, FAU crystals appeared to have become hollow

324 starting from a single crystal edge, or more commonly, apex of the octahedral crystals. A similar 
325 observation of hollow crystals, previously described for silicalite-1 (MFI), was tentatively

326 explained by the presence of increased concentrations of defect sites at the inside of the crystal

327 where growth was initiated,[40] possibly coupled with an improved crystallinity at the outer

328 surfaces by local Ostwald ripening, or protection of the external surface by interaction with the

329 structure directing cation $\mathrm{TPA}^{+}$.[41] In the current case however, the hollow crystals most

330 probably result from a non random $\mathrm{Al}$ distribution in the framework, which is typical for zeolites

331 made with crown-ether templates.[42, 43]
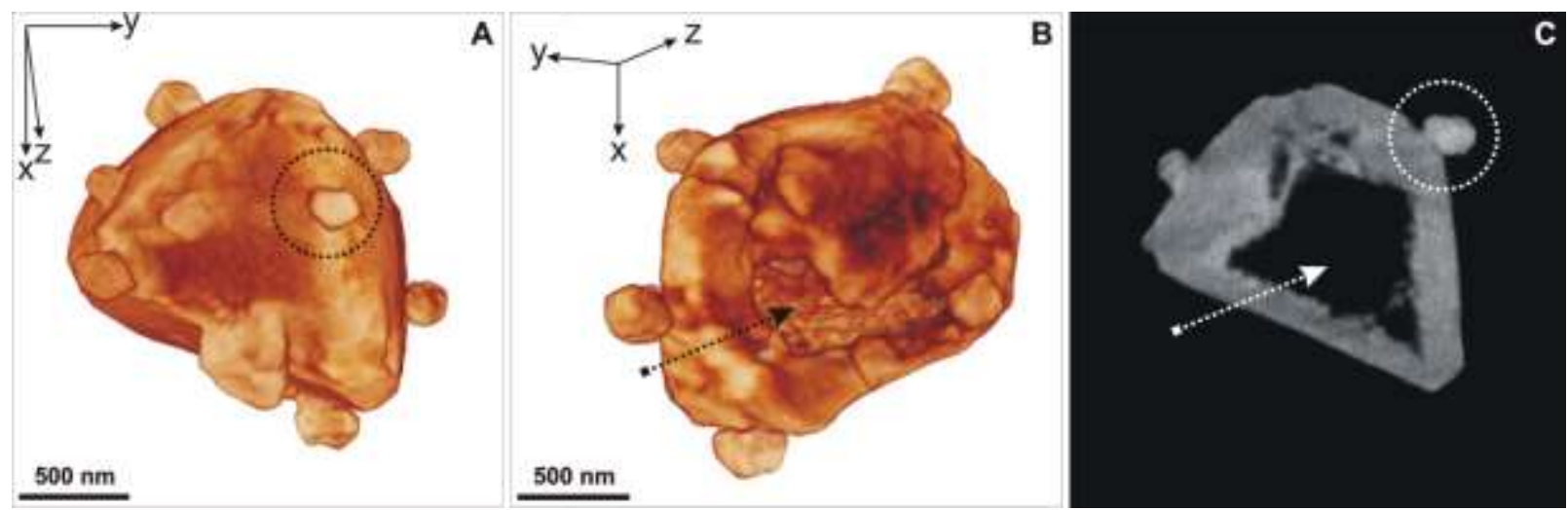

333 Figure 7. Visualizations of the 3D tomographic reconstruction from a FAU crystal depicted

334 along different orientations are given in (A) and (B). A slice through the $3 \mathrm{D}$ reconstruction is 335 presented in $(\mathrm{C})$, in which both the hollow structure of the crystal and newly formed CHA crystal 336 are indicated.

${ }^{29} \mathrm{Si}$ MAS NMR determined $\mathrm{Si} / \mathrm{Al}$ ratios in the solid phase show a decrease from 3.5 in the

338 FAU starting material to 2.0 at the onset of CHA formation (Table SI- 3). At that time, NaY is

339 virtually fully exchanged into the potassium form $(\mathrm{K} / \mathrm{Na} \geq 40) .{ }^{27} \mathrm{Al} \mathrm{MAS} \mathrm{NMR}$ of subsamples

340 taken as function of time, demonstrated a preservation of the tetrahedral Al-coordination during

341 the transformation process. The $\mathrm{Si} / \mathrm{Al}$ ratio of phase pure chabazite obtained after 72 hours is

3421.66 , and is unchanged after 8 days. 
343 As mentioned earlier, chabazite is formed over a broad range of conditions in presence of $\mathrm{K}^{+}$.

344 For example, the liquid/solid ratio of 60 used in the experiment described above, can be varied

345 between 9 and 120, still yielding full conversion of FAU to chabazite. Moreover, lower total

346 hydroxide concentrations and mixed $\mathrm{K}, \mathrm{Na}$ environments enabled chabazite formation too,

347 thereby corroborating the observed CHA formation obtained in $\mathrm{YCW}$. While the combination of

348 FAU transformation experiments in pure hydroxide and simulated YCW solutions provides

349 significant indications for consistent formation of CHA, confirming the long-term stability of

350 CHA in YCW, the crystallization of a significant fraction of MER observed during the

351 transformation in $\mathrm{YCW}$ media at temperatures as low as $60^{\circ} \mathrm{C}$, was unexpected. It must however

352 be noted that concrete pore water also contains small amounts of $\mathrm{Ca}^{2+}$ cations, in addition to $\mathrm{K}^{+}$

353 and $\mathrm{Na}^{+}$. While $\mathrm{Ca}^{2+}$ has been demonstrated to exert a stabilizing effect on the FAU

354 structure,[44-46] as confirmed by the absence of chabazite formation upon exposure of Ca-

355 exchanged zeolite $\mathrm{Y}$ to $\mathrm{KOH}$ (Figure SI 5), it may now be speculated to also influence the ratio

356 of MER/CHA upon hyperalkaline transformation in $\mathrm{K}^{+}, \mathrm{Na}^{+}$media. However, for now it remains

357 unclear which parameter facilitated the formation of merlinoite next to chabazite in pore water

358 environment. Future research should focus on the influence of $\mathrm{Na} / \mathrm{K} / \mathrm{Ca}$ ratio, $\mathrm{OH}^{-}$content, and

359 temperature on the ratio of CHA/MER in the final transformation products, as well as in the

360 silica speciation in presence of these cations. Since it is clear that the formation conditions of

361 these two zeolites are close, it will be extremely difficult to exclude long-term interconversion

362 between these phases. As result, safety assessment of any long-term application of zeolites as

363 sorption sink in hyper-alkaline media will require to document the sorption properties of both

364 phases, to allow construction of a conservative performance assessment scenario. Also the

365 hydroxyl induced changes to the frameworks pointed out by ${ }^{137} \mathrm{Cs}$, should be elucidated. 


\section{Supporting Information.}

368 Typical porewater compositions for state I porwaters. Evolution of the $\mathrm{Cs}^{+}$sorption isotherm as

369 function of time and $\mathrm{pH}$. Spectroscopic and analytical data recorded during the transformation

370 process from FAU to CHA. Animated version of the $3 \mathrm{D}$ tomographic reconstruction from a

371 hollow FAU crystal with newly formed CHA crystals on the crystal faces. This material is

372 available free of charge via the Internet at http://pubs.acs.org.

\section{Toc Art}

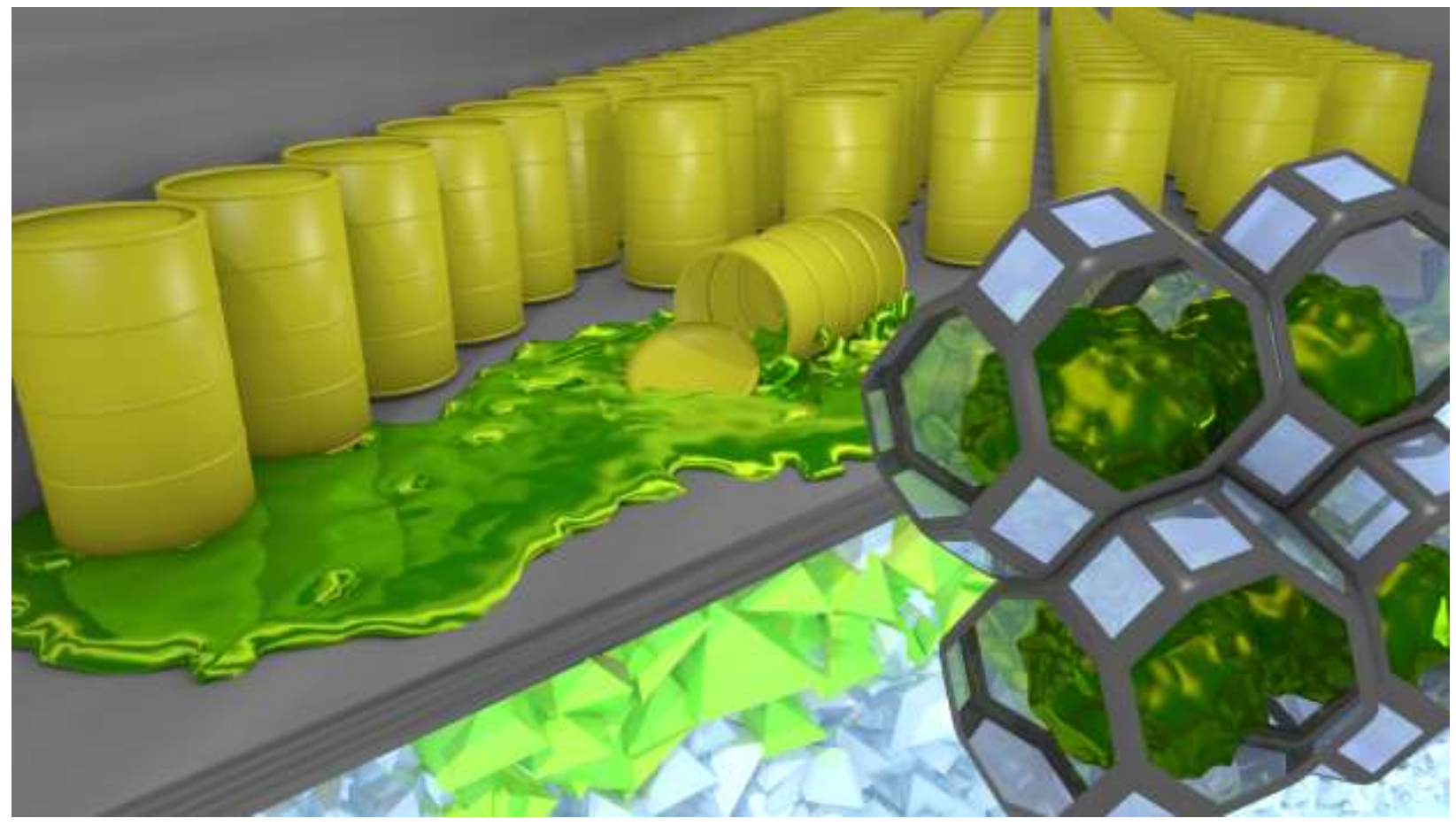

375 AUTHOR INFORMATION

\section{Corresponding Author}

377 * eric.breynaert@biw.kuleuven.be. KULeuven - Center for surface chemistry and catalysis.

378 Kasteelpark arenberg 23 - box 2461. B-3001 Leuven. Tel: +32 16321598 Fax: +32 16321998 . 
380 The manuscript was written through contributions of all authors. All authors have given approval 381 to the final version of the manuscript.

\section{Funding Sources}

383 This work was supported by long-term structural funding by the Flemish Government 384 (Methusalem) and by ONDRAF/NIRAS, the Belgian Agency for Radioactive Waste and Fissile 385 Materials, as part of the program on surface disposal of Belgian Category A waste. The Belgian 386 government is acknowledged for financing the interuniversity poles of attraction (IAP-PAI).

387 G.V.T. and S.B. acknowledge financial support from European Research Council (ERC 388 Advanced Grant \# 24691-COUNTATOMS, ERC Starting Grant \#335078-COLOURATOMS).

\section{ACKNOWLEDGMENT}

L. Van Tendeloo and E. Breynaert acknowledge a mandate as, respectively, an aspirant and a postdoctoral fellow of FWO Vlaanderen. This work was partially performed in cooperation with ONDRAF/NIRAS.

\section{REFERENCES}

394 1. Nemerow, N. L.; Agardy, F. J., Strategies of industrial and hazardous waste 395 management. Van Nostrand Reinhold: New York, 1998; p 748.

396 2. Williams, P. T., Waste treatment and disposal. 2nd ed.; Wiley: Chichester, West Sussex, 397 England; Hoboken, NJ, USA, 2005; p 380.

398 3. Sumerling, T. Project near surface disposal of category A waste at Dessel; NIROND-TR 399 2007-06 E December; Ondraf/Niras: Brussels, 2006; p 90.

400 4. Niras/Ondraf The cAt project in Dessel: A long-term solution for Belgian category A 401 waste; NIROND 2010- 02 E March; Brussels, 2010; p 140.

402 5. Atkins, M.; Glasser, F. P., Application of portland cement-based materials to radioactive 403 waste immobilization. Waste Manage. (Oxford) 1992, 12, 105-131.

404 6. Kim, D.; Quinlan, M.; Yen, T. F., Encapsulation of lead from hazardous CRT glass 405 wastes using biopolymer cross-linked concrete systems. Waste Manage. (Oxford) 2009, 29, (1), 406 321-328. 
7. Berner, U. R., Evolution of pore water chemistry during degradation of cement in a radioactive waste repository environment. Waste Manage. (Oxford) 1992, 12, (2-3), 201-219.

8. Jacques, D.; Wang, L.; Martens, E.; Mallants, D., Modelling chemical degradation of concrete during leaching with rain and soil water types. Cem. Concr. Res. 2010, 40, (8), 13061313.

9. Maes, A.; Cremers, A., Site group interaction effects in zeolite-Y. Part 2.-Na-Ag selectivity in different site groups. Journal of the Chemical Society, Faraday Transactions 1: Physical Chemistry in Condensed Phases 1978, 74, (0), 136-145.

10. Sawhney, B. L., Potassium and cesium ion selectivity in relation to clay mineral structure. Clays Clay Miner. 1970, 18, 47-52.

11. Pohl, C. A.; Stillian, J. R.; Jackson, P. E., Factors controlling ion-exchange selectivity in suppressed ion chromatography. J. Chromatogr. A 1997, 789, (1-2), 29-41.

12. Fritz, J. S., Factors affecting selectivity in ion chromatography. J. Chromatogr. A 2005, 1085, (1), 8-17.

13. Mimura, H.; Akiba, K., Adsorption Behavior of Cesium and Strontium on Synthetic Zeolite P. J. Nucl. Sci. Technol. 1993, 30, (5), 436-443.

14. Samanta, S. K., Cesium sorption behavior of a mordenite type synthetic zeolite and its modified form obtained by acid treatment. J. Radioanal. Nucl. Chem. 1999, 240, (2), 585-588.

15. Mimura, H.; Kanno, T., Distribution and Fixation of Cesium and Strontium in Zeolite A and Chabazite. J. Nucl. Sci. Technol. 1985, 22, (4), 284-291.

16. Ames, L. L. J., Effect of base cation on the cesium kinetics of clinoptilolite. The American Mineralogist 1962, 47, 1310-1316.

17. Hoyle, S.; Grutzeck, M. W., Effects of Phase Composition on the Cesium Leachability of Cement-Based Waste Forms. In Waste management '86: waste isolation in the U.S., technical programs and public education : proceedings of the Symposium on Waste Management at Tucson, Arizona, March 2-26 1986, Arizona Board of Regents: 1986; pp 491-496.

18. Borai, E. H.; Harjula, R.; Malinen, L.; Paajanen, A., Efficient removal of cesium from low-level radioactive liquid waste using natural and impregnated zeolite minerals. J. Hazard. Mater. 2009, 172, (1), 416-22.

19. Hsu Liu, D. C. C. H. P. C. N., Evaluation of cesium sorption on natural mordenite. $J$. Radioanal. Nucl. Chem. 1994, 185, 319-329.

20. Abusafa, A.; Yücel, H., Removal of $137 \mathrm{Cs}$ from aqueous solutions using different cationic forms of a natural zeolite: clinoptilolite. Sep. Purif. Technol. 2002, 28, (2), 103-116.

21. Mimura, H.; Yamagishi, I.; Akiba, K., Removal of Cesium and Strontium from HighActivity-Level water by zeolites. Bulletin of the Research Institute of Mineral Dressing and Metallurgy 1988, 44, (1), 1-7.

22. Chang, H.-s.; Um, W.; Rod, K.; Serne, R. J.; Thompson, A.; Perdrial, N.; Steefel, C. I.; Chorover, J., Strontium and Cesium Release Mechanisms during Unsaturated Flow through Waste-Weathered Hanford Sediments. Environ. Sci. Technol. 2011, 45, (19), 8313-8320.

23. Faghihian, H.; Ghannadi Marageh, M.; Kazemian, H., The use of clinoptilolite and its sodium form for removal of radioactive cesium, and strontium from nuclear wastewater and $\mathrm{Pb} 2+, \mathrm{Ni2} 2, \mathrm{Cd} 2+, \mathrm{Ba} 2+$ from municipal wastewater. Appl. Radiat. Isot. 1999, 50, (4), 655-660.

24. Bostick, D. T.; Arnold Jr., W. D.; Taylor, P. A.; McTaggart, D. R.; Burgess, M. W.; Guo, B. In Evaluation of Improved Techniques for the Removal of 90Sr and 137Cs from Process Wastewater and Groundwater: Chabazite Zeolite Baseline Study, Energy, 1995; 1995; p 35. 
25. Misaelides, P., Application of natural zeolites in environmental remediation: A short review. Microporous Mesoporous Mater. 2011, 144, 15-18.

26. Fernández, R.; Rodríguez, M.; Vigil De La Villa, R.; Cuevas, J., Geochemical constraints on the stability of zeolites and $\mathrm{C}-\mathrm{S}-\mathrm{H}$ in the high $\mathrm{pH}$ reaction of bentonite. Geochim. Cosmochim. Acta 2010, 74, (3), 890-906.

27. Wallace, S. H.; Shaw, S.; Morris, K.; Small, J. S.; Burke, I. T., Alteration of sediments by hyperalkaline K-rich cement leachate: implications for strontium adsorption and incorporation. Environ. Sci. Technol. 2013, 47, 3694-700.

28. Van Tendeloo, L.; Gobechiya, E.; Breynaert, E.; Martens, J. A.; Kirschhock, C. E. A., Alkaline cations directing the transformation of FAU zeolites into five different framework types. Chem. Commun. 2013, 1-3.

29. Honda, K.; Itakura, M.; Matsuura, Y.; Onda, A.; Ide, Y.; Sadakane, M.; Sano, T., Role of structural similarity between starting zeolite and product zeolite in the interzeolite conversion process. Journal of nanoscience and nanotechnology 2013, 13, (4), 3020-6.

30. Sano, T.; Itakura, M.; Sadakane, M., High Potential of Interzeolite Conversion Method for Zeolite Synthesis. Journal of the Japan Petroleum Institute 2013, 56, 183-197.

31. Feijen, E. J. P.; De Vadder, K.; Bosschaerts, M. H.; Lievens, J. L.; Martens, J. A.; Grobet, P. J.; Jacobs, P. A., Role of 18-Crown-6 and 15-Crown-5 Ethers in the Crystallization of Polytype Faujasite Zeolites. J. Am. Chem. Soc. 1994, 116, 2950-2957.

32. Robson, H. E., Verified syntheses of zeolitic materials. Elsevier: 2001; p 272.

33. Bourgogne, M.; Guth, J. L.; Wey, R. Process for the preparation of synthetic zeolites, and zeolites obtained by said process. 4503 024, 1985.

34. Parkhurst, D. L.; Appelo, C. A. J. User's guide to PHREEQC (Version 2) : a computer program for speciation, batch-reaction, one-dimensional transport, and inverse geochemical calculations; Denver, Colorado, 1999.

35. Cizmek, A.; Subotic, B.; Aiello, R.; Crea, F.; Tuoto, C., Dissolution of high-silica zeolites in alkaline solutions I. Dissolution of silicalite-1 and ZSM-5 with different aluminum content. Microporous Mater. 1995, 4, 159-168.

36. Haouas, M.; Lakiss, L.; Martineau, C.; El Fallah, J.; Valtchev, V.; Taulelle, F., Silicate ionic liquid synthesis of zeolite merlinoite: Crystal size control from crystalline nanoaggregates to micron-sized single-crystals. Microporous Mesoporous Mater. 2014, 198, (0), 35-44.

37. Skofteland, B. M.; Ellestad, O. H.; Lillerud, K. P., Potassium merlinoite: crystallization, structural and thermal properties. Microporous Mesoporous Mater. 2001, 43, (1), 61-71.

38. Li, P.; Ding, T.; Liu, L.; Xiong, G., Investigation on phase transformation mechanism of zeolite NaY under alkaline hydrothermal conditions. Mater. Charact. 2013, 86, 221-231.

39. Wang, Y.; Li, X.; Xue, Z.; Dai, L.; Xie, S.; Li, Q., Preparation of zeolite ANA crystal from zeolite $\mathrm{Y}$ by in situ solid phase iso-structure transformation. J. Phys. Chem. B 2010, 114, (17), 5747-54.

40. Wang, Y.; Tuel, A., Nanoporous zeolite single crystals: ZSM-5 nanoboxes with uniform intracrystalline hollow structures. Microporous Mesoporous Mater. 2008, 113, (1-3), 286-295.

41. Dai, C.; Zhang, A.; Li, L.; Hou, K.; Ding, F.; Li, J.; Mu, D.; Song, C.; Liu, M.; Guo, X., Synthesis of Hollow Nanocubes and Macroporous Monoliths of Silicalite-1 by Alkaline Treatment. Chem. Mater. 2013, 25, (21), 4197-4205.

42. Feijen, E. J. P.; Lievens, J. L.; Martens, J. a.; Grobet, P. J.; Jacobs, P. a., Silicon and Aluminum Ordering in Frameworks of FAU and EMT Aluminosilicate Zeolites Crystallized in the Presence of Crown Ethers. The Journal of Physical Chemistry 1996, 100, 4970-4975. 
498 43. Groen, J. C.; Bach, T.; Ziese, U.; Paulaime-van Donk, A. M.; de Jong, K. P.; Moulijn, J. 499 A.; Pérez-Ramírez, J., Creation of Hollow Zeolite Architectures by Controlled Desilication of 500 Al-Zoned ZSM-5 Crystals. J. Am. Chem. Soc. 2005, 127, (31), 10792-10793.

501 44. Chiyoda, O.; Davis, M. E., Hydrothermal conversion of Y-zeolite using alkaline-earth 502 cations. Microporous Mesoporous Mater. 1999, 32, (3), 257-264.

503 45. Singh, R.; Dutta, P. K., Stabilization of natural Faujasite zeolite: possible role of alkaline 504 earth metal ions. Microporous Mesoporous Mater. 1998, 21, (1-3), 103-109.

505 46. Denayer, J. F. M.; Depla, A.; Vermandel, W.; Gemoets, F.; van Buren, F.; Martens, J.; 506 Kirschhock, C.; Baron, G. V.; Jacobs, P. A., Removal of cyclopentadiene from 1-octene by 507 transition metal containing zeolites-Part 2: Stabilization of CoCaX zeolite by its cation 508 distribution. Microporous Mesoporous Mater. 2007, 103, (1-3), 11-19. 
511 Supporting Information - Chabazite: Stable cation-

512 exchanger in hyper alkaline concrete pore water

513 Leen Van Tendeloo, ${ }^{1}$ Wauter Wangermez, ${ }^{1}$ Mert Kurttepeli, ${ }^{2}$ Benny de Blochouse, ${ }^{1}$ Sara Bals, ${ }^{2}$

514 Gustaaf Van Tendeloo, ${ }^{2}$ Johan A. Martens, ${ }^{1}$ André Maes, ${ }^{1}$ Christine E.A. Kirschhock, ${ }^{1}$ Eric

515 Breynaert ${ }^{1, *}$.

$516{ }^{1}$ Centre for Surface Chemistry and Catalysis, KU Leuven, Kasteelpark Arenberg 23, 3001

517 Heverlee.

$518{ }^{2}$ Electron Microscopy for Materials Science (EMAT), University of Antwerp,

519 Groenenborgerlaan 171, 2020 Antwerp;

Table SI- 1: Typical pore water composition (state I, $\mathrm{pH} 13,25^{\circ} \mathrm{C}$ ) calculated using PhreeqC with the Lawrence Livermore National Laboratory database 1lnl.dat.

\begin{tabular}{|l|l|l|l|l|l|l|l|l|}
\hline & Speciation & Molality & & Speciation & Molality & & Speciation & Molality \\
\hline $\mathrm{Ca}$ & & $1,5 \times 10^{-3}$ & $\mathrm{~K}$ & & $1,8 \times 10^{-1}$ & $\mathrm{Na}$ & & $7,02 \times 10^{-2}$ \\
\hline \multirow{4}{*}{$\mathrm{Ca}^{2+}$} & $7,08 \times 10^{-4}$ & & $\mathrm{~K}^{+}$ & $1,72 \times 10^{-1}$ & & $\mathrm{Na}^{+}$ & $6,87 \times 10^{-2}$ \\
\cline { 2 - 8 } & & & $\mathrm{KSO}_{4}^{-}$ & $2,52 \times 10^{-4}$ & & $\mathrm{NaSO}_{4}^{-}$ & $8,55 \times 10^{-5}$ \\
\cline { 2 - 8 } & $\mathrm{CaSO}_{4}$ & $6,14 \times 10^{-6}$ & & $\mathrm{KOH}$ & $7,31 \times 10^{-3}$ & & $\mathrm{NaHCO}_{3}$ & $1,98 \times 10^{-9}$ \\
\cline { 2 - 8 } & $\mathrm{CaHCO}_{3}^{+}$ & $1,03 \times 10^{-10}$ & & $\mathrm{KHSO}_{4}$ & $8,98 \times 10^{-18}$ & & $\mathrm{NaCO}_{3}^{-}$ & $5,33 \times 10^{-6}$ \\
\cline { 2 - 8 } & $\mathrm{CaCO}_{3}$ & $1,15 \times 10^{-5}$ & & & & & $\mathrm{NaOH}$ & $1,45 \times 10^{-3}$ \\
\cline { 2 - 8 } & $\mathrm{CaOH}^{+}$ & $7,74 \times 10^{-4}$ & & & & & \\
\hline
\end{tabular}

523 Table SI- 2: Typical pore water composition (state I, $\mathrm{pH} 8,25^{\circ} \mathrm{C}$ ) calculated using PhreeqC with 524 the Lawrence Livermore National Laboratory database llnl.dat.
Speciation
Molality
Speciation
Molality
Speciation
Molality 


\begin{tabular}{|c|c|c|c|c|c|c|c|c|}
\hline $\mathrm{Ca}$ & & $1,5 \times 10^{-3}$ & $\mathrm{~K}$ & & $1,8 \times 10^{-1}$ & $\mathrm{Na}$ & & $7,01 \times 10^{-2}$ \\
\hline & $\mathrm{Ca}^{2+}$ & $1,08 \times 10^{-3}$ & & $\mathrm{~K}^{+}$ & $1,8 \times 10^{-1}$ & & $\mathrm{Na}^{+}$ & $7,00 \times 10^{-2}$ \\
\hline & $\mathrm{CaNO}_{3}{ }^{+}$ & $4,07 \times 10^{-4}$ & & $\mathrm{KSO}_{4}^{-}$ & $2,57 \times 10^{-4}$ & & $\mathrm{NaSO}_{4}^{-}$ & $8,51 \times 10^{-5}$ \\
\hline & $\mathrm{CaSO}_{4}$ & $9,07 \times 10^{-6}$ & & $\mathrm{KOH}$ & $3,12 \times 10^{-8}$ & & $\mathrm{NaHCO}_{3}$ & $4,73 \times 10^{-6}$ \\
\hline & $\mathrm{CaHCO}_{3}{ }^{+}$ & $3,67 \times 10^{-7}$ & & $\mathrm{KHSO}_{4}$ & $2,22 \times 10^{-12}$ & & $\mathrm{NaCO}_{3}^{-}$ & $5,24 \times 10^{-8}$ \\
\hline & $\mathrm{CaCO}_{3}$ & $1,67 \times 10^{-7}$ & & & & & $\mathrm{NaOH}$ & $6,06 \times 10^{-9}$ \\
\hline & $\mathrm{CaOH}^{+}$ & $4,83 \times 10^{-9}$ & & & & & & \\
\hline
\end{tabular}

525 Table SI- 3: Si distribution and $\mathrm{Si} / \mathrm{Al}$ ratio of the samples during transformation of zeolite $\mathrm{Y}$ $526 \quad(\mathrm{Si} / \mathrm{Al}=3.5)$ determined by ${ }^{29} \mathrm{Si}$ MAS NMR.

\begin{tabular}{|l|c|c|c|c|c|c|}
\hline & $\mathrm{Q}^{0 \mathrm{Al}}(\%)$ & $\mathrm{Q}^{1 \mathrm{Al}}(\%)$ & $\mathrm{Q}^{2 \mathrm{Al}}(\%)$ & $\mathrm{Q}^{3 \mathrm{Al}}(\%)$ & $\mathrm{Q}^{4 \mathrm{Al}}(\%)$ & $\mathrm{Si} / \mathrm{Al}$ \\
\hline Na-Y (calc) 0h & 16.39 & 54.84 & 25.70 & 3.08 & 0 & $\mathbf{3 . 4 6}$ \\
\hline FAU 22 h & 2.47 & 27.37 & 42.90 & 19.96 & 7.30 & $\mathbf{1 . 9 7}$ \\
\hline CHA 72 h & 3.63 & 14.61 & 33.64 & 33.56 & 14.55 & $\mathbf{1 . 6 6}$ \\
\hline CHA 8 days & 2.77 & 13.62 & 32.96 & 33.96 & 16.69 & $\mathbf{1 . 6 1}$ \\
\hline
\end{tabular}



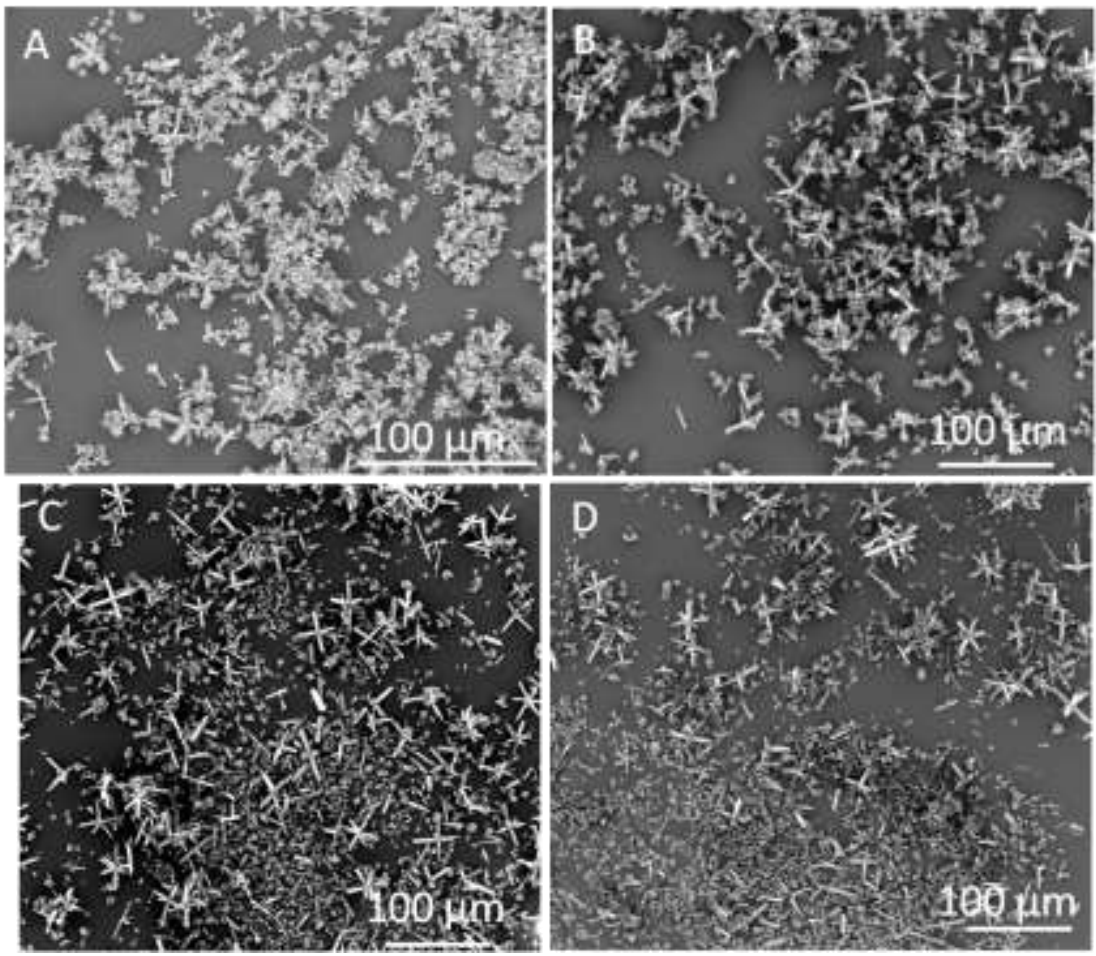

$530 \quad$ Figure SI 1: SEM images of transformation products after 0 hours (A), 7 hours (B) and 72 hours

531 (C) are presented above. The fast-fourier transforms from the corresponding areas indicated at 532 (B) unveil the CHA content of the newly formed particles. The transformation product formed at $53360^{\circ} \mathrm{C}$ in 857 days (A) contains more chabazite relative to merlinoite than the products at $85^{\circ} \mathrm{C}$ 534 after 150 days (B), 228 days (C) and 509 days (C). 


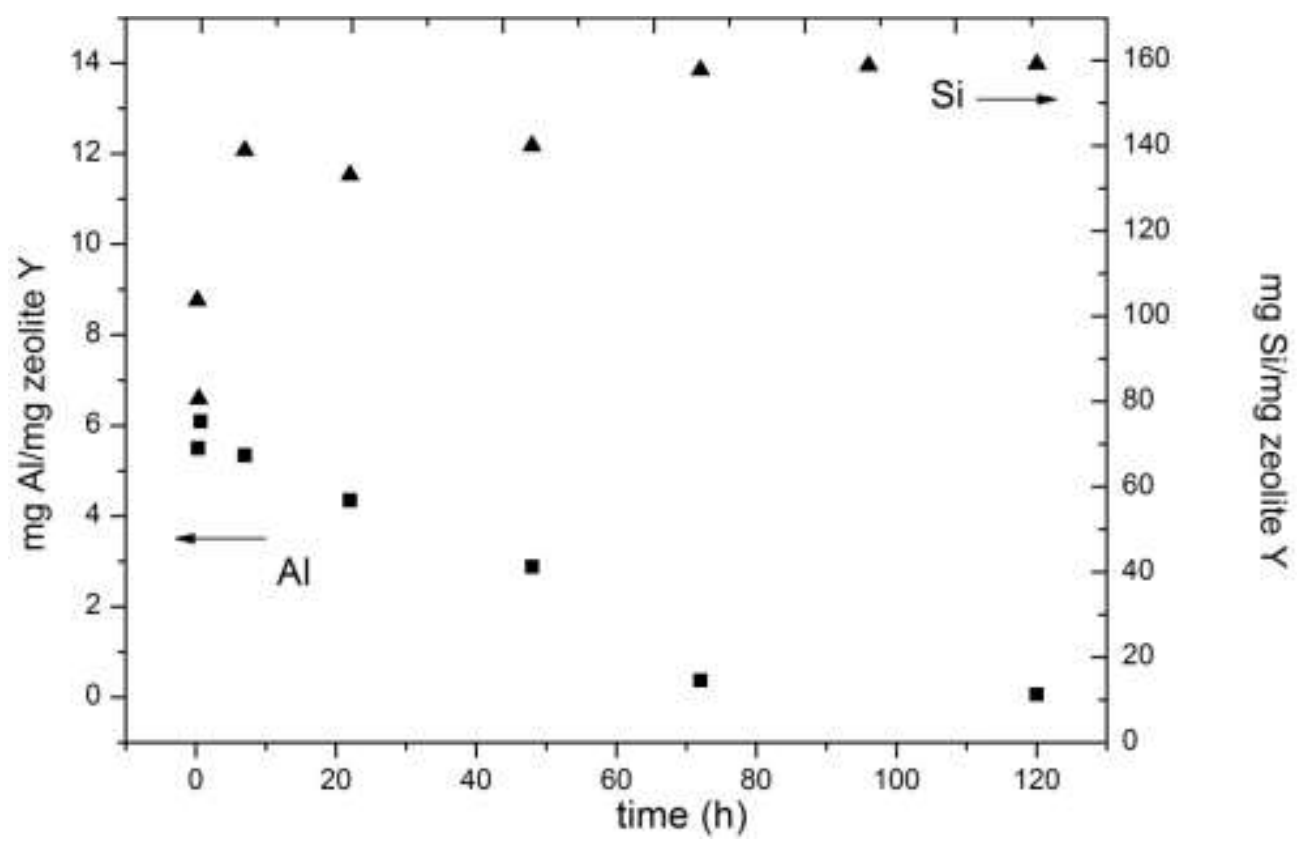

Figure SI 2: Concentrations of $\mathrm{Al}(\mathbf{\square})$ and $\mathrm{Si}(\mathbf{\Lambda})$ in the liquid phase during the transformation

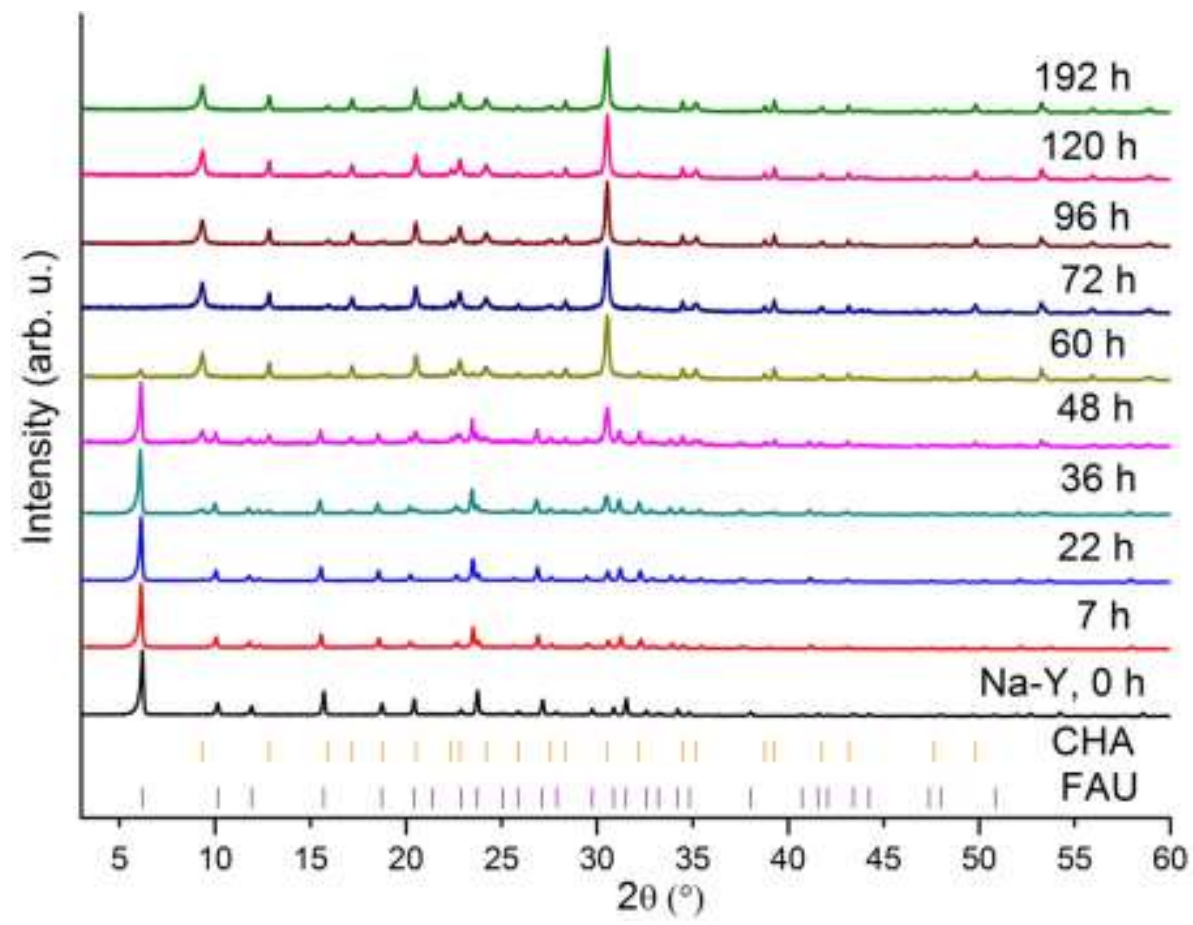

Figure SI 3. Time series of transformation of zeolite $\mathrm{Y}(\mathrm{Si} / \mathrm{Al}=3.5)$ into chabazite in pure $\mathrm{KOH}$ as monitored by PXRD. The transformation occurs within 72 hours. 

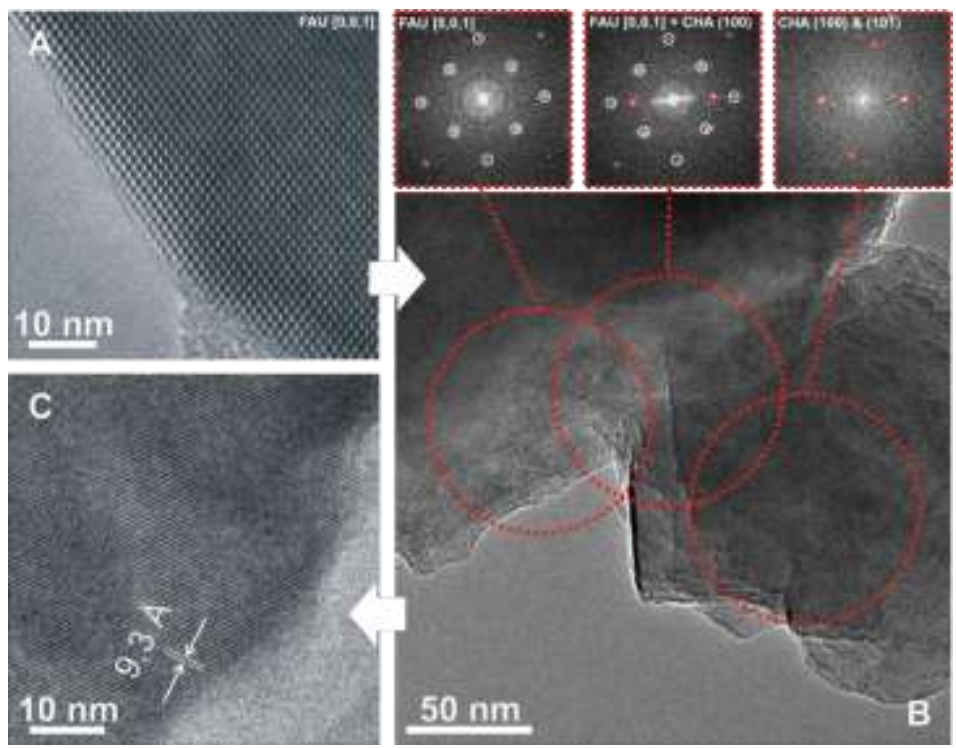

546 Figure SI 4: High-resolution TEM images of transformation products after 0 hours (A), 7 hours 547 548 (B) and 72 hours (C) are presented above. The fast-fourier transforms from the corresponding areas indicated at (B) unveil the CHA content of the newly formed particles.

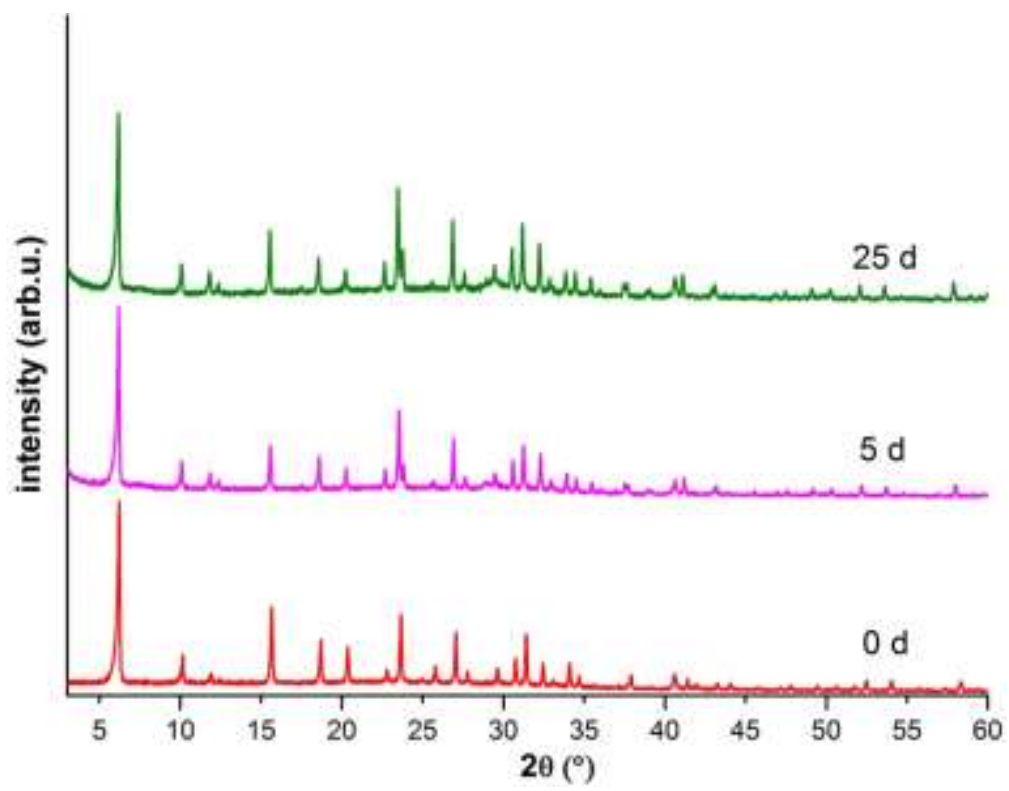

551 Figure SI 5. Ca-Y (dried at $60^{\circ} \mathrm{C}$, non-calcined) does not transform to chabazite within 25 days, 552 whereas under the applied conditions, Na-Y is fully converted into chabazite in 96 hours. 